\title{
Prostaglandins and the central nervous system
}

\author{
E. MARLeY \\ M.A., M.D., D.Sc., F.R.C.P., F.R.C.Psych. D.P.M. \\ S. Poole \\ B.Sc. \\ J. D. STEPHENSON \\ B.Sc., Ph.D \\ Department of Pharmacology, Institute of Psychiatry, London SE5
}

Prostaglandins (PGs) are natural constituents of the brain and spinal cord. They are released from the central nervous system (CNS) spontaneously, in response to electrical and chemical stimulation and during fever. In addition to their action on brainstem neurones when applied iontophoretically (Avanzino, Bradley and Wolstencroft, 1966) they have potent CNS effects which are now considered.

\section{Body temperature}

Probably the current most investigated aspect of PGs is their effect on body temperature $\left(T_{b}\right)$. Thus PGEs infused into the brain of many species at various ambient temperatures $\left(T_{a}\right)$, elevated $T_{b}$ (Feldberg, 1975), the site of action (preoptic and anterior hypothalamic areas) being ostensibly indistinguishable from that for fever evoked by endogenous pyrogens. Exceptions to such a general finding are of interest in that some overlooked pharmacological feature of PGs may emerge. The adult spiny anteater is one such exception, since intraventricular $\mathrm{PGE}_{1}$ and $\mathrm{PGE}_{2}$ lowered $\mathrm{T}_{\mathrm{b}}$ over a wide range of $T_{a}$ although intravenous bacterial pyrogen (Eberthella typhi) induced fever (Baird, Hales and Lang, 1974). In the young chick, another non-placental animal, PGEs infused into the hypothalamus at thermoneutrality elevated $T_{b}$, whereas below thermoneutrality such infusion lowered $T_{b}$, partly by physical and partly by chemical thermoregulatory mechanisms (Artunkal and Marley, 1974).

During fever produced by endotoxin or endogenous pyrogen, increased PG-like activity occurs in the cerebrospinal fluid (CSF) (Feldberg, 1975). The current hypothesis is that these agents enhance synthesis of PGs in brain, particularly within the preoptic/anterior hypothalamic area, through stimulation of the rate-controlling step releasing the precursor fatty acids; the PGs formed act locally on neurones to produce fever. PGs synthetized at other sites may act there to affect behaviour, or may do so at sites reached after transfer into the CSF.
The aspirin-like drugs reduce fever and prevent release of PGEs into the CSF. Their therapeutic action is ascribed to inhibition of prostaglandin synthetase (Vane, 1971), brain synthetase being more sensitive to aspirin-like drugs than that of other tissues (Flower and Vane, 1972). If PG synthesis is an essential link in the action of pyrogen then it should not be possible to dissociate fever and brain synthesis of PGs. This has proved not to be the case for rabbits in which sustained fever was induced by intravenous infusion of endogenous pyrogen, yet the prior infusion of sodium salicyclate sufficient to inhibit PG synthesis by at least $50 \%$ did not significantly diminish fever although preventing an increase in PGs in the CSF (Cranston, Hellon and Mitchell, 1975). Another problem is that fever induced by intraventricular pyrogen was unaffected by the simultaneous administration of PG antagonists in doses which abolished PG-induced fever (Cranston et al., 1976). To complicate matters further, extensive lesions of the preoptic/anterior hypothalamic area rendered rabbits insensitive to the hyperthermic effects of intraventricular or intrahypothalamic infused PGEs but not to intraventricular or intravenous leucocyte pyrogen (Veale and Cooper, 1975). Various explanations for these discrepant findings were canvassed, although the possibility that the present account of the involvement of PGs in fever has been too simplified must now be considered seriously.

The most clear-cut dissociation between fever induced by bacterial pyrogen and the actions of PGEs was observed in the spiny anteater (see above); and in young chicks tested below thermoneutrality, PGEs infused intrahypothalamically antagonized or reversed endotoxin fever (Artunkal, Marley and Stephenson, 1975, 1977a). Moreover, fever was obtained, in chicks, with Shigella when PG synthesis had been arrested (Ali and Stephenson, unpublished data). Thus while there is much evidence to link bacterial fever with PGs, the association is not absolute. 


\section{Behaviour}

Intense behavioural and electrocortical sleep are induced in a number of species when PGEs but not PGFs are infused intraventricularly or into the hypothalamus. Catatonia has also been described in cats (Horton and Main, 1965). Probably as a consequence of their soporific action, PGEs potentiate barbiturate sleep, protect against chemicallyand electrically-induced convulsions (Holmes and Horton, 1968; Poddibiuk, 1976) and reverse arousal evoked by dexamphetamine (Artunkal, Marley and Stephenson, 1977b). Conditioned avoidance and escape responses are depressed (Potts and East, 1971). Additionally, PGEs (and PGFs in some of the tests) impair motor coordination, reduce spontaneous activity, locomotor activity and exploratory activity (Holmes and Horton, 1968; Poddibiuk, 1976).

The mechanism of the soporific effect is unknown although, apart from a direct effect of PGEs, reduced transmitter release could be responsible (Bergström, Farnebo and Fuxe, 1973). Alterations of blood supply through arteriolar vasoconstriction may be contributory.

\section{Analgesia}

Intraventricular PGs $\left(E_{1}, E_{2}, F_{1 \alpha}, F_{2 \alpha}\right)$ produced analgesia in rats, measured by the hot-plate method (Poddibiuk, 1976).

\section{Food intake}

This is reduced following $\mathrm{PGE}_{1}$ infused into the medial and lateral hypothalamus of rats (Baile et al., 1973) but increased with infusions into similar sites in sheep (Martin and Baile, 1973).

\section{Endocrine effects}

PGEs and PGFs given by various routes, including infusion into the median eminence and into the third cerebral ventricle, led to the release into the circulation of various hormones from the adenohypophysis (ACTH, LH, FSH, GH, prolactin) and from the neurohypophysis (ADH, oxytocin) (Wolfe, 1975). Application directly to the anterior pituitary neural lobe and basal hypothalamic regions was without effect.

\section{Spinal cord reflexes}

The effect of PGEs given intravenously and intraaortically to chicks and cats depended on whether they were intact and chloralosed, or made spinal. Thus, in spinal preparations, a mono- and a polysynaptic spinal reflex were enhanced whereas in intact animals these were diminished. These different effects could be attributed to a supraspinal and therefore indirect action of $\mathrm{PGE}_{2}$ in intact animals but a direct action on the spinal cord in the spinal preparations (Holmes and Horton, 1968; Duda, ํㅜㄹ Horton and McPherson, 1958). PGFs enhanced a spinal cord reflex in spinal and in intact chicks but $\frac{\varrho}{C}$ the effects in cats were variable. The conclusion is $\ddot{\Rightarrow}$ that the main effect of the PGEs and the PGFs is excitation of spinal cord $\alpha$-moto-neurones. Studies $\bar{O}$ with PGs on the frog isolated superfused spinal cord accord with this view (Phillis and Tebécis, 1968; Coceani and Viti, 1973).

\section{References}

Artunkal, A.A. \& Marley, E. (1974) Hyper- and hypothermic effects of prostaglandin $E_{1}\left(P_{1} E_{1}\right)$ and their potentiation by indomethacin in chicks. Journal of Phy siology. London, 242, 141.

Artunkal, A.A., Marley, E. \& Stephenson, J.D. (1975) if Dissociation of bacterial pyrexia from prostaglandin $E$ activity. British Journal of Pharmacology, 54, 250.

Artunkal, A.A., Marley, E. \& Stephenson, J.D. (1977a) Some effects of prostaglandin $E_{1}$ and $E_{2}$ and of endotoxin infused into the hypothalamus of young chicks; dissociation between endotoxin fever and the effects of prosta- 윽 glandin. British Journal of Pharmacology, 61, 39.

Artunkal, A.A., Marley, E. \& Stephenson, J.D. (1977b) Some effects of intravenous prostaglandin $\mathrm{E}_{1}$ and endotoxin in young chicks. British Journal of Pharmacology, 61, 29.

Avanzino, G.L., Bradley, P.B. \& Wolstencroft, J.F (1966) Action of prostaglandins $E_{1}, E_{2}$ and $F_{2 \alpha}$ on braiß stem neurones. British Journal of Pharmacology and $\vec{\theta}$ Chemotherapy, 27, 157.

Baile, C.A., Simpson, C.W., Bean, S.M., Mclaughlis C.L. \& JACOBS, H. (1973) Prostaglandins and food intake of rats: a component of energy balance regulation. Physiology and Behaviour, 10. 1077.

BaIRD, J.A., Hales, J.R.S. \& LANG, W.J. (1974) Thermoregulatory responses to the injection of monoamines, acetylcholine and prostaglandins into a lateral cerebral ventricle of the echidna. Journal of Physiology. London, 236, 539.

Bergström, S., Farnebo, L.A. \& FuXe, K. (1973) Effect of prostaglandin $\mathrm{E}_{2}$ on central and peripheral catecholamine neurones. European Journal of Pharmacology, 21, 362.

Coceani, F. \& Viti, A. (1973) Actions of prostaglandin $E_{1}$ on spinal neurones in the frog. Advances in Bioscience, 9, 481.

Cranston, W.I., Helion, R.F. \& Mitchell, D. (1975) A dissociation between fever and prostaglandin concen- 3 tration in cerebrospinal fluid. Journal of Physiology. London, 253, 583.

Cranston, W.I., Duff, G.W., Hellon, R.F., Mitchell, D. \& ToWNSEND, Y. (1976) Evidence that brain prostaglandin synthesis is not essential in fever. Journal of Physiology. London, 259, 239.

DudA, P., Horton, E.W. \& McPherson, A. (1968) The effects of prostaglandins $E_{1}, F_{1 \alpha}$ and $F_{2 \alpha}$ on monosynaptic $N$ reflexes. Journal of Physiology. London, 196, 151.

FeldberG, W. (1975) The Ferrier Lecture, 1974. Body N temperature and fever: changes in our views during the N last decade. Proceedings of the Royal Society, 191, 199.

FLOWER, R.J. \& VANE, J.R. (1972) Inhibition of prostaglandin synthetase in brain explains the anti-pyretic activity of 0 paracetamol (4-acetamidophenol). Nature. London, 240, 410.

Holmes, S.W. \& Horton, E.W. (1968) Prostaglandins and the central nervous system. In: Prostaglandin Symposium 
of the Worcester Foundation for Experimental Biology, Ed. P. W. Ramwell \& J. E. Shaw. Pp. 21-38. Interscience, New York.

Horton, E.W. \& MaIn, I.H.M. (1965) Differences in the effects of prostaglandin $F_{2 \alpha}$, a constituent of cerebral tissue and prostaglandin $\mathrm{E}_{1}$ of conscious cats and chicks. International Journal of Neuropharmacology, 4, 65.

MarTin, F.H. \& BaIle, C.A. (1973) Feeding elicited in sheep by intrahypothalamic injections of $\mathrm{PGE}_{1}$. Experientia, 29, 306.

Phillis, J.W. \& Tebecis, A.K. (1968) Prostaglandins and toad spinal cord reflexes. Nature. London, 217, 1076.

PoDdibiuk, Z.M. (1976) A comparison of the central actions of prostaglandins $A_{1}, E_{1}, E_{2}, F_{1 \alpha}$ and $F_{2 \alpha}$ in the rat. Psychopharmacology, 50, 89.
PotTs, W.J. \& EAST, P.F. (1971) Effects of prostaglandins and prostaglandin precursors on the conditioned avoidance response (CAR) in rats. Pharmacologist, 13, 392.

VANE, J.R. (1971) Inhibition of prostaglandin synthesis as a mechanism of action for aspirin-like drugs. Nature, New Biology, 231, 232.

Veale, W.L. \& CoOPER, K.E. (1975) Comparison of sites of action of prostaglandin $\mathrm{E}$ and leucocyte pyrogen in brain. In: Temperature Regulation and Drug Action (Ed by P. Lomax, E. Schönbaum and J. Jacob), pp. 218-240. Karger, Basel.

WOLFE, L.H. (1975) Possible roles of prostaglandins in the nervous system. In: Advances in Neurochemistry (Ed. by D. W. Agranof and M. H. Aprison) 1, pp. 1-49. Plenum Press, New York. 